\title{
Evaluation of human serum S100B protein as a prognostic factor in nonmetastatic breast cancer patients
}

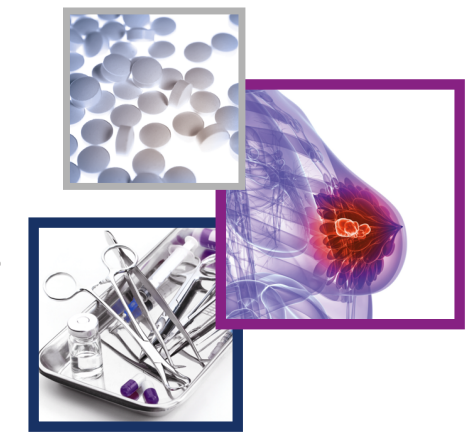

\author{
Fatemeh Homaei Shandiz ${ }^{1,2}$, Kamran Ghaffarzadegan ${ }^{3}$, Saeed Jahani Fariman ${ }^{4}$, \\ Mahdi Jannati ${ }^{4}$, Sepideh Elyasi ${ }^{4}$ \& Amir Hooshang Mohammadpour*,4,5 \\ ${ }^{1}$ Solid Tumor Treatment Research Center, Mashhad University of Medical Sciences, Mashad, Iran \\ ${ }^{2}$ Department of Clinical Oncology, Faculty of Medicine, Mashhad University of Medical Sciences, Mashhad, Iran \\ ${ }^{3}$ Research \& Education Department, Razavi Hospital, Mashhad, Iran \\ ${ }^{4}$ Department of Clinical Pharmacy, School of Pharmacy, Mashhad University of Medical Sciences, Mashhad, Iran \\ ${ }^{5}$ Pharmaceutical Research Center, Pharmaceutical Research Institute, Mashhad University of Medical Sciences, Mashhad, Iran \\ *Author for correspondence: Tel.: +98 513882 3255; Fax: +98 513882 3251; MohamadpoorAH@mums.ac.ir
}

\begin{abstract}
Aim: The aim of this study was the evaluation of S100B prognostic role in nonmetastatic breast cancer patients, excluding confounding factors. Patients \& method: 79 breast cancer patients, who fulfilled inclusion and exclusion criteria, were enrolled in the study. Before any adjuvant chemotherapy or surgery, the serum level of S100B was determined. All patients were followed up for 5 years, particularly regarding cancer recurrence and patients' survival. Results: $42 \%$ of the patients experienced no recurrence after 5 years and cumulative risk of recurrence was 0.86 . There was no significant correlation between serum level of protein S100B and recurrence rate in 5 years $(p=0.59)$. Conclusion: According to the results, the serum levels of S100B protein may have no prognostic role in nonmetastatic breast cancer.
\end{abstract}

First draft submitted: 17 March 2018; Accepted for publication: 6 November 2018; Published online: 5 March 2019

Keywords: nonmetastatic breast cancer • prognostic factor $\bullet$ S100B protein

Breast cancer is the most commonly diagnosed cancer worldwide, including low- and middle-income countries [1]. It is the fifth most common cause of cancer-related death overall with approximately 6-19 per 100,000 mortality rate and the leading cause of cancer death in women [2-4].

Breast cancer is a heterogeneous disease and different patients do have different prognosis and survival ratios. Unfortunately, lots of patients are not treated properly, with some overtreated (when they would have been cured solely with local therapy) and others undertreated (e.g., not treated in the adjuvant setting). It would be of great value to have reliable prognostic factors that could help select those patients most at risk for recurrence [5]. There are many factors that affect breast cancer prognosis, such as patients' age and race, progesterone receptor and lymphatic metastasis situation, tumor size, nodal status, HER2 expression and DNA-ploidy situation [6,7]. Several molecular markers related to poor prognosis of breast cancer have been proposed. Such markers are usually indicators of growth, invasion and metastatic potential [7]. Recent researches showed that S100 protein is not only related to tumorigenesis, development, invasion and metastasis of breast tumor, but also closely associated with prognosis of patients [6].

S100 gene family is the largest subfamily of type EF-hand calcium-binding proteins with at least 25 distinct members [8]. This family includes inflammatory molecules, which contribute to the development of a proinflammatory tumor microenvironment [9]. They perform a wide range of intracellular and extracellular functions [10,11]. Levels of S100B serum, a homodimer of the S100B chain, have been evaluated in patients with melanoma at different stages and have been shown to increase in a stage-dependent manner. Its increased level is associated with the presence of metastases, reduced survival and reflects tumor load, stage and prognosis. This allows S100B to be used as a diagnostic marker and in the staging of malignant melanoma. S100B has also considered a valuable marker in assessing a patient's response to treatment [12].

Future Medicine 
Decreased levels of S100B following treatment correlates with a good response to therapy and increased survival [10-12]. In a recent study it is demonstrated that $S 100 \mathrm{~B}$ treatment suppresses the migratory capacity of estrogen receptor-negative breast cancer and that $\mathrm{S} 100 \mathrm{~B}$ expression may serve a predictive marker for metastasis in breast cancer [9]. Moreover, due to the high frequency of asymptomatic CNS involvement in breast cancer, it is suggested that serum S100B could have a prognostic value and be an interesting serum biomarker in breast cancer with CNS metastasis [13]. Its prognostic role in patients with metastatic breast cancer, especially with metastasis to the brain, was also evaluated in other studies and its negative prognostic role was proposed in this population [14,15]. But, to the best of our knowledge, these studies have not considered important confounding factors including inflammatory and autoimmune diseases, psychiatric disorders, other malignancies and brain damage, which may be strongly effective on serum levels of these biomarkers, nor evaluated its prognostic value in nonmetastatic breast cancer patients.

This study is the first clinical study of the relationship between serum levels of S100B protein, and recurrence and survival of nonmetastatic breast cancer patients considering various probable confounding factors.

\section{Material \& method}

Study design

It was a longitudinal study conducted from April 2005 to July 2014 at a Cancer Institute, Omid Hospital and Oncology Department of Ghaem Hospital affiliated to Mashhad University of Medical Sciences, Iran. The study protocol was approved by the local Ethics Committee of Mashhad University of Medical Sciences (code: 85169). All participants signed written consent forms.

\section{Study population}

Patients with a diagnosis of breast cancer based on clinical and preclinical data who met the inclusion criteria, aged between 25 and 70 years and with nonmetastatic breast cancer, were enrolled in the study. All diagnosed patients were classified using the American Joint Committee on Cancer (AJCC) staging manual based on The National Comprehensive Cancer Network (NCCN) criteria. Patients in first and second stage were evaluated for distant metastasis using physical examination and history, and patients in third stage by mean of bone scans and CT scans of the thorax, pelvis and abdomen. Presence of brain metastasis was ruled out by brain MRI. It is noteworthy to mention that patients with autoimmune disease, malignancies other than breast cancer, hypertension, cardiovascular disease, diabetes, liver disease, or cerebral ischemia were excluded.

\section{Study protocol}

A questionnaire containing demographic data and patients' characteristics (including age, weight, height, family history of cancer, age at first pregnancy), pathological findings (including histologic grade, lymph node involvement and metastasis) and cytology (including steroid receptor, HER2, P53 and Ki67 status) was completed for all patients. $10 \mathrm{ml}$ of peripheral blood was collected from all patients and centrifuged at 10,000 r.p.m. for $10 \mathrm{~min}$. The plasma fraction was separated and stored at $-70^{\circ} \mathrm{C}$ until required for analysis. Patients were evaluated for recurrence every 6 months by a clinical oncologist for 5 years and at each follow-up session physical examination and, if necessary, mammography, ultrasound, CT scan and laboratory tests were performed.

\section{Determination of human S100B serum concentration}

Serum level of human S100B was measured with an ELISA kit (BioVendor, Japan); each assay was calibrated using S100B standard curve following the manufacturer's instructions. The calibration curve is presented in Figure 1 and the calibration range is $10-320 \mathrm{pg} / \mathrm{ml}$. EDTA plasma and citrate plasma are not suitable kinds of samples because of unfavorable interactions between sample and dilution buffer components. The antibodies used in this ELISA are specific for human S100B with no detectable crossreactivities to human S100A1, S100A4, S100A5, S100A8, S100A9, S100A10, S100A11, S100A14, S100A15, S100A16 and S100G. The spiking recovery of the kit is $102.5 \%$. The kit was kept at a temperature of $2-8^{\circ} \mathrm{C}$ before its application. It should be mentioned that the serum level of the protein 8-oxo-2'-deoxyguanosine (8-oxodG) was also determined in these samples simultaneously. These findings were published in this journal previously [16]. 


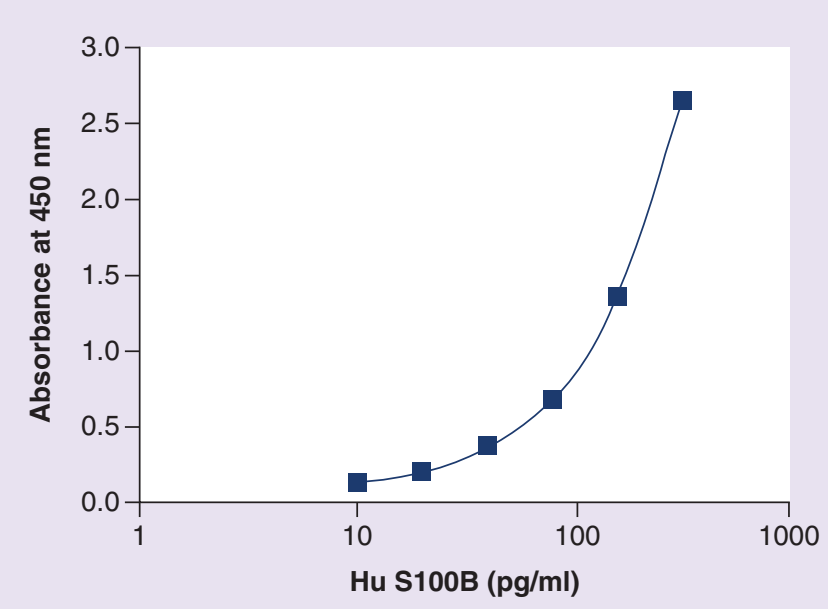

Figure 1. A calibration curve for the serum S100B commercial ELISA.

\section{Sample size}

Based on available data from the previous pilot study, a reported $\sigma$ (risk rate) 1.5593 , assuming $\alpha$ error of $5 \%$ and study power of $80 \%(\beta=0.20)$, the calculated sample size was 80 according to the following formula:

$$
\mathrm{N}=2\left(\mathrm{z}_{1-\alpha / 2}+\mathrm{z}_{1-\beta}\right)^{2} /(\operatorname{Ln} \sigma)^{2}
$$

\section{Statistical analysis}

Statistical analysis was carried out by SPSS16. Kaplan-Meier method was used to estimate patients' survival and hazard estimation. Moreover, for investigation of the relationship between breast cancer risk factors and serum biomarkers Cox regression model was used. The Wald test was used for evaluation of the relationship between breast cancer risk factors and serum biomarkers and survival rate. It should be noted that in all analyses $\mathrm{p}<0.05$ was considered statistically significant.

\section{Results}

\section{Characteristics of the study population}

79 eligible patients, following the inclusion/exclusion criteria, completed the study. All patients admitted in this study were diagnosed with nonmetastatic breast cancer, and invasive ductal carcinoma was the most common type of malignancy in these patients. About $55 \%$ of patients were diagnosed with Stage 2 breast cancer. The most common chemotherapy regimen administered to patients was 'adriamycin, cyclophosphamide, paclitaxel' (AC-Taxol; 44.3\%). The mean age of patients admitted to the study was $46.47 \pm 9.39$ years old and all patients were females. The mean serum level of S100B was $41.94 \pm 16.89 \mathrm{ng} / \mathrm{ml}$. Demographic characteristics, risk factors for breast cancer and prognostic factors related to breast cancer are summarized in Tables 1 and 2.

\section{Evaluation of survival \& hazard function}

By using the Kaplan-Meier method, it can be estimated that $42 \%$ of the patients experienced no recurrence after 5 years. Figure 2 shows 5 -year survival and annual recurrence rate for study population.

Cumulative risk of recurrence 5 years after diagnosis of breast cancer was 0.86 (Figure 3).

Evaluation of the correlation between recurrence \& 5-year survival with breast cancer risk factors \& serum S100B protein in study population

After performing the collinearity test, affecting factors in Cox regression model were identified and entered in a Cox regression model. These include factors such as age, BMI, family history, stage of breast cancer, whether or not they were estrogen receptor-positive, age at first pregnancy, number of pregnancies and HER2, Ki67 and p53 statuses. 


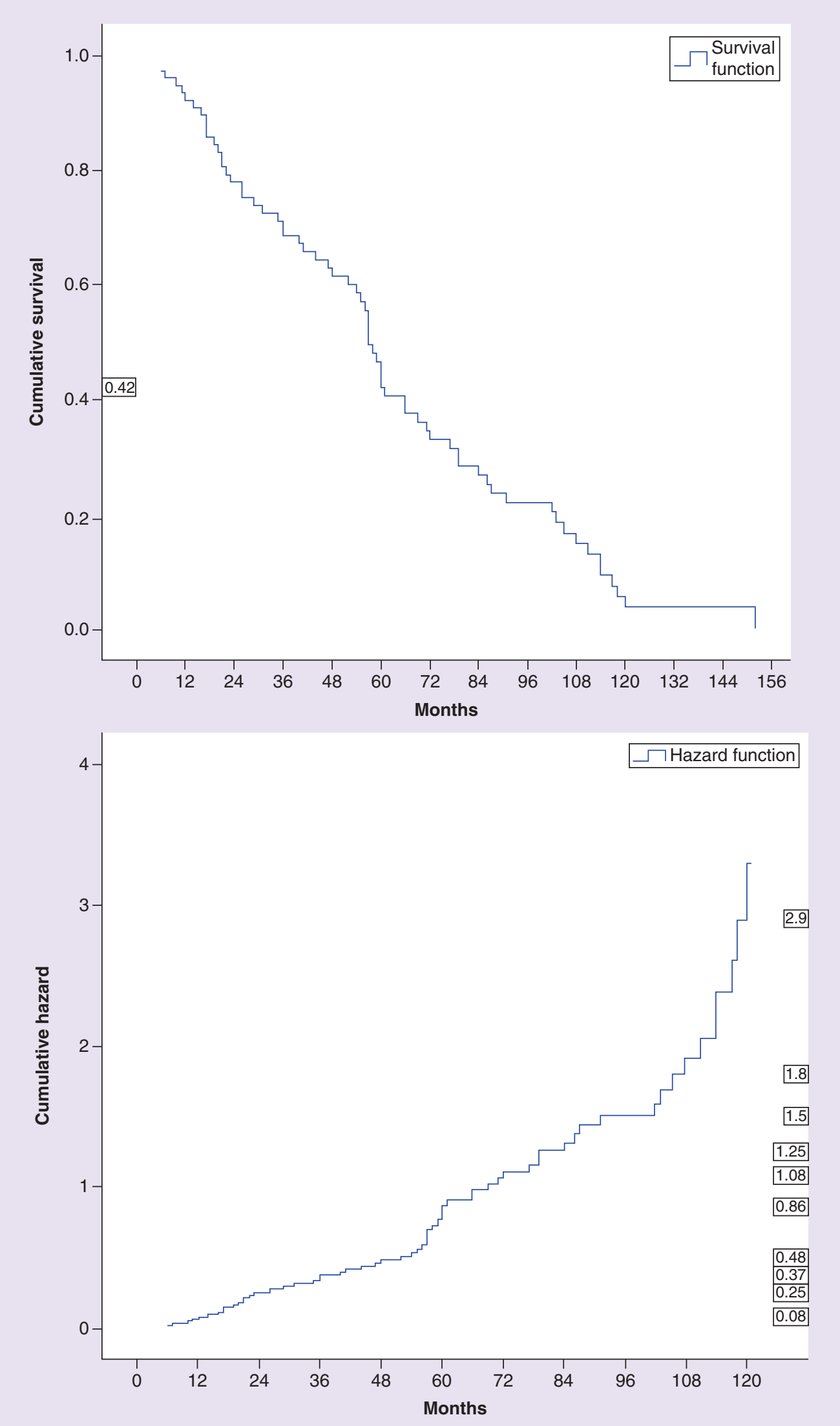

Figure 2. Kaplan-Meier estimates of disease-free survival in primary breast cancer patients $(n=79)$. 


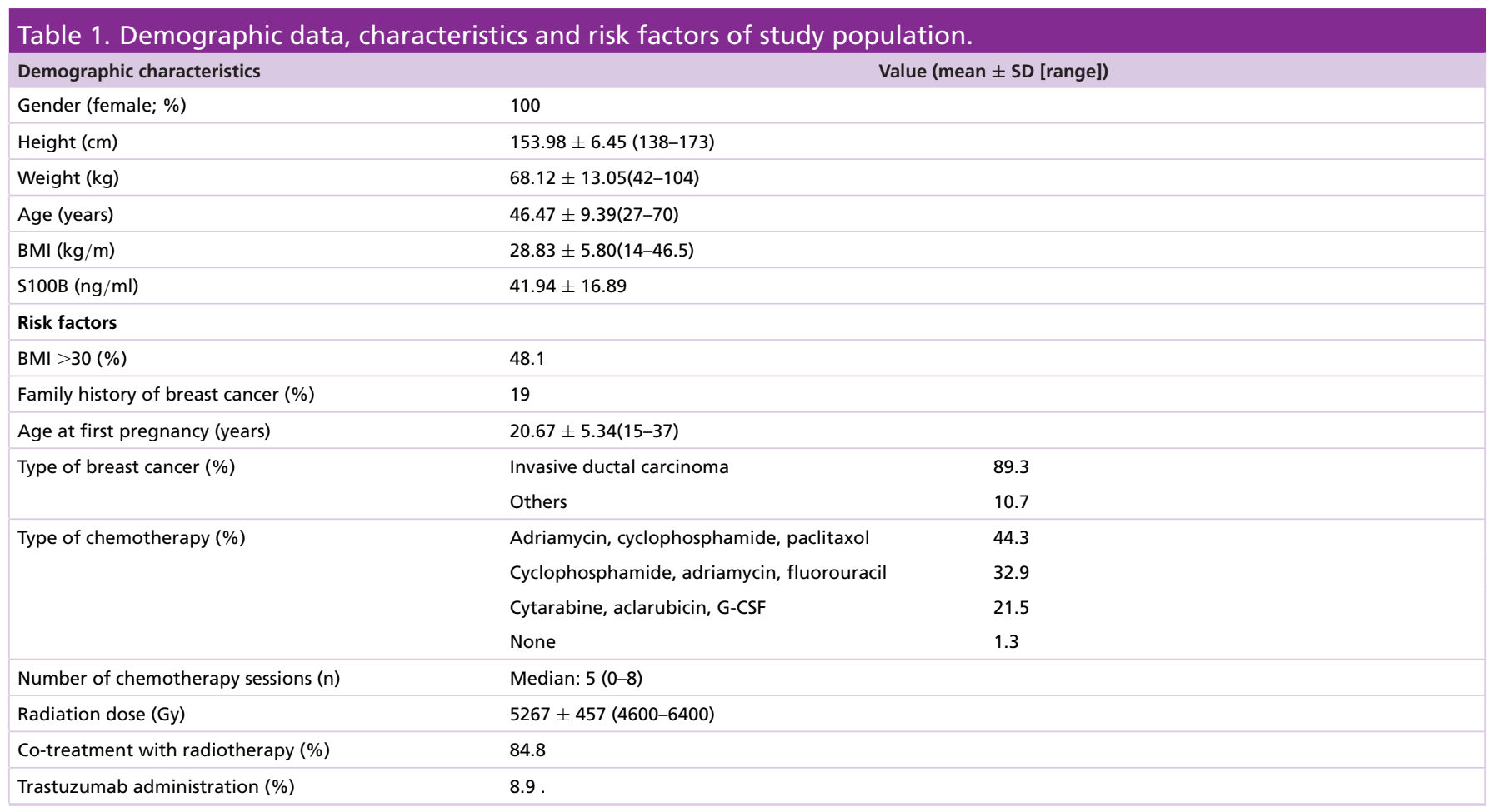

\section{Table 2. Prognostic factors in study population.}

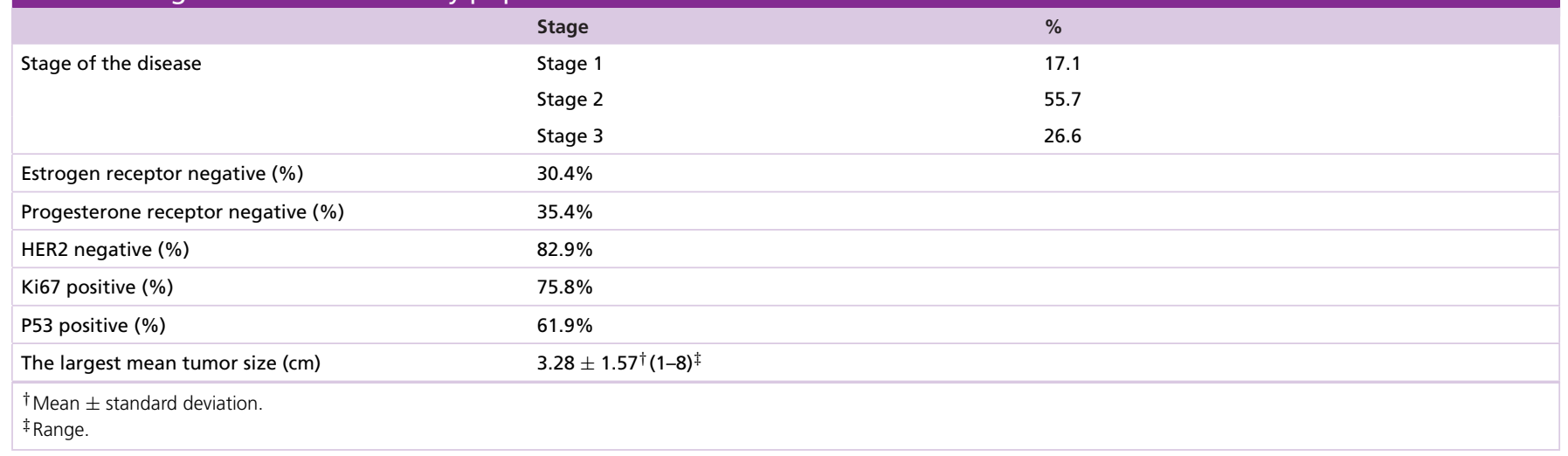

General appropriateness of the model was evaluated based on Enter method, which was statistically significant ( $p$ $=0.037$ ).

Table 3 shows results of the Wald test. Age, BMI, positive family history and number of pregnancies were effective on 5-year survival rate but serum S100B level had an insignificant negative effect in regression equation ( $p$-value $=0.596 ; \beta=-0.01)$. The same result was found in subgroup of patients with ductal carcinomas $(p=0.601)$. Moreover, there was no correlation between these factors and recurrence rate or 5-year survival ( $p$-value $>0.05)$.

Evaluation of correlation between serum level of S100B protein \& other demographic data \& risk factors in study population

The S100B serum levels of the patients were compared with several known tumor characteristics. The presence of lymph node metastases, expression of estrogen receptor, progesterone receptor, HER-2, Ki-67 and p53 were classified as either positive or negative for statistical analyses. The grading and tumor size were divided into the following subgroups: Grade I group, Grade II-III group, T1 group and T2-4 group.

There was no correlation between serum level of S100B protein and age of patients $(\mathrm{p}=0.23)$. Moreover, S100B level was higher in patients with breast cancer Grade 3 in comparison with patients with lower grades; however, the 


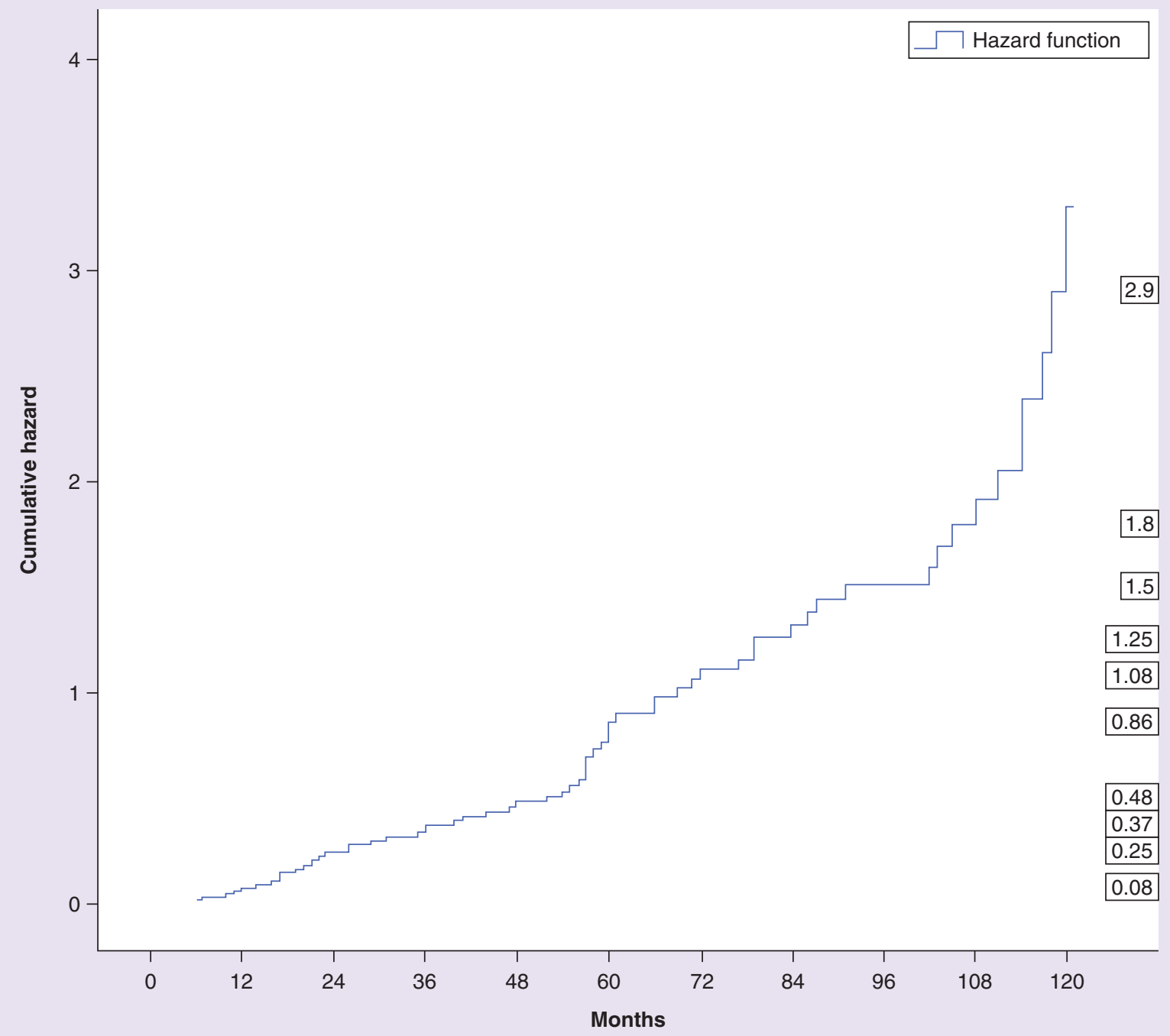

Figure 3. Kaplan-Meier estimates of recurrence in primary breast cancer patients $(n=79)$.

\section{Table 3. Correlation between recurrence rate and 5-year survival with breast cancer risk factors.}

\begin{tabular}{|c|c|c|c|c|c|}
\hline Variable & p-value ${ }^{\dagger}$ & Degree of freedom & Standard error & $\beta$ & Wald statistic \\
\hline Age & $0.001 *$ & 1 & 0.64 & 0.21 & 10.72 \\
\hline BMI & $0.02 *$ & 1 & 0.18 & 0.41 & 5.42 \\
\hline Family history & 0.06 & 1 & 1.16 & -2.15 & 3.41 \\
\hline Stage of breast cancer & 0.66 & 1 & 0.49 & -0.22 & 0.19 \\
\hline Estrogen & 0.32 & 1 & 0.63 & 0.64 & 1.03 \\
\hline receptor-positive & 0.25 & 1 & 0.06 & -0.07 & 1.30 \\
\hline Age at first pregnancy & $0.002 *$ & 1 & 0.22 & -0.65 & 9.18 \\
\hline Number of pregnancy & 0.18 & 1 & 0.69 & 0.93 & 1.83 \\
\hline p53 & 0.63 & 1 & 0.54 & -0.26 & 0.23 \\
\hline HER2 & 0.11 & 1 & 1.16 & 1.84 & 2.56 \\
\hline Ki67 & 0.6 & 1 & 0.01 & -0.01 & 0.28 \\
\hline S100B & & & & & \\
\hline
\end{tabular}




\begin{tabular}{|c|c|c|c|}
\hline Prognostic factors & & Mean S100B $\left(\mathrm{ng} / \mathrm{ml}^{-1}\right)$ & p-value \\
\hline Tumor size & $1(n=17)$ & $57.29 \pm 83.12$ & 0.152 \\
\hline \multirow[t]{2}{*}{ Nodal status } & $0(n=41)$ & $47.71 \pm 61.94$ & 0.275 \\
\hline & $1-3(n=32)$ & $35.38 \pm 30.31$ & \\
\hline Grade & $1-2(n=63)$ & $40.89 \pm 54.62$ & 0.719 \\
\hline \multirow[t]{2}{*}{ Estrogen receptor expression } & Positive $(n=54)$ & $38.1 \pm 52.6$ & 0.302 \\
\hline & Negative $(n=25)$ & $42.36 \pm 42.36$ & \\
\hline \multirow[t]{2}{*}{ Progesterone receptor expression } & Positive $(n=50)$ & $37.63 \pm 54.15$ & 0.302 \\
\hline & Negative $(n=29)$ & $49.79 \pm 40.41$ & \\
\hline Ki-67 & Positive $(n=60)$ & $41.08 \pm 29.58$ & 0.793 \\
\hline \multirow[t]{2}{*}{ p53 } & Positive $(n=52)$ & $54.31 \pm 67.29$ & 0.656 \\
\hline & Negative $(n=27)$ & $46.25 \pm 48.56$ & \\
\hline \multirow[t]{2}{*}{ Histology } & Ductal $(n=72)$ & $38.58 \pm 48.53$ & $0.035^{*}$ \\
\hline & Others $(n=7)$ & $82.83 \pm 50.84$ & \\
\hline \multirow[t]{2}{*}{ Hormone-replacement therapy use } & Received $(n=57)$ & $40.71 \pm 17.03$ & 0.857 \\
\hline & Not received $(n=22)$ & $49.93 \pm 16.89$ & \\
\hline \multirow[t]{2}{*}{ Age } & Premenopause $(n=63)$ & $45.05 \pm 53.22$ & 0.144 \\
\hline & Postmenopause $(n=16)$ & $29.69 \pm 31.32$ & \\
\hline
\end{tabular}

difference was not significant $(\mathrm{p}=0.719)$. It should be noted that $S 100 \mathrm{~B}$ level was significantly lower in patients with ductal carcinoma in comparison with other histology $(\mathrm{p}=0.035)$.

S100B serum level was not significantly different in patients who received hormone replacement therapy or not and in ER, PR, HER-2, Ki-67 and p53-positive patients in comparison with negative patients, based on independent sample T test ( $\mathrm{p}=0.857 ; 0.302 ; 0.302 ; 0.849$ and 0.656 , respectively).

Mean serum S100B levels and standard deviation in the groups of conventional prognostic factors are summarized in Table 4.

\section{Discussion}

In this study prognostic role of $\mathrm{S} 100 \mathrm{~B}$ protein in nonmetastatic breast cancer is evaluated. As can be found from aforementioned results, we found no significant correlation between its serum level and recurrence rate in 5 years $(\mathrm{p}=0.59 ; \mathrm{p}>0.05)$.

Based on our findings, serum concentration of $\mathrm{S100B}$ protein does not have prognostic value in nonmetastatic breast cancer. The reason for the difference between our finding and most of previous studies that proposed S100 protein family as prognostic factor in different cancers may be due to excluding these confounding factors. Moreover, most previous studies have focused on other $\mathrm{S} 100$ protein members and, in the limited studies which evaluated S100B, were carried out on patients with other type of cancers or metastatic breast cancer. In one study performed by Mcllroy et al. in 2010, tumor tissue expression of S100B was related to reduced time to disease recurrence (hazard ratio: 5.82; $\mathrm{p}<0.0001$ ) and it was a stronger predictor of disease-free survival than any of the classic parameters of disease recurrence, including tumor size, nodal and HER2 status. Based on these strong associations between S100B tissue expression and reduced disease-free survival in breast cancer, they assessed preoperative levels of serum S100B in a cohort study on 80 primary breast cancer patients. Kaplan-Meier estimates of disease-free survival reveal that elevated serum levels of $\mathrm{S} 100 \mathrm{~B}$ are a powerful predictor of poor survival (hazard ratio: 5.3; $\mathrm{p}$ $=0.004$; Figure 2) and serum level of S100B is associated with disease recurrence ( $\mathrm{p}=0.017)$ [14]. However, in this study probable confounding factors were not excluded. 
In another study Darlix et al. evaluated S100B protein beside some other markers including cancer antigen 15-3 (CA15-3), carcinoembryonic antigen, HER2 extra-cellular domain, neuron-specific enolase and matrix metalloproteinase 9 (MMP-9) serum levels in order to determine their prognostic value. With a median follow-up of 40.8 months, median overall survival was 16.2 months and they also reported that S100B serum levels were independently associated with a poor outcome (HR: 1.93; 95\% CI: 1.05-3.54; $\mathrm{p}=0.033$ ). However, they mentioned that result must be considered with doubt as the two groups identified by S100B serum levels were obviously unbalanced regarding the number of patients $(\mathrm{n}=19$ for S100B $>0.12 \mu \mathrm{g} / \mathrm{l}$ compared with $\mathrm{n}=224$ for normal S100B). Besides, although they found its significant prognostic value in multivariate analysis, its clinical impact was considered questionable, as rarely elevated biomarkers appear to be of limited use in clinical practice. It is interesting to note that the analysis of S100B with the cutoff of $0.072 \mu \mathrm{g} / \mathrm{l}$, even though it defined two more balanced groups regarding the number of patients, did not reach significance in multivariate analysis. Moreover, their study included high number of patients with brain metastasis (35\%), which is associated with a poor outcome. Among patients with brain metastasis, 73 cases (82.9\%) had an S100B serum level $>0.12 \mu \mathrm{g} / 1$ [15]. Actually, $\mathrm{S} 100 \mathrm{~B}$ elevation in serum is a marker for an alteration of the blood-brain barrier, as an astrocytic marker and its serum level has been widely studied in various neurological diseases. $\$ 100 \mathrm{~B}$ is highly available in the nervous system where it is dominantly expressed in astrocytes, oligodendrocytes and Schwann cells. S100B is released from brain tissue into cerebrospinal fluid (CSF) and blood following brain damage of different origin, that is, brain infarction, intracerebral or subarachnoidal hemorrhage, neurotrauma and large intracerebral tumors. There is a documented relationship between degree of cell damage and S100B levels in CSF. Actually its micromolar concentration is neurotoxic and participates in neurodegenerative disease pathology [15,17-19]. Therefore, Darlix and colleagues hypothesized that the reported negative prognostic value of high serum S100B in their study may be linked to the presence of brain metastasis in their study population. This conclusion can justify our findings as our patients suffered from nonmetastatic breast cancer. As mentioned in the Method section, patients in Stages 1 and 2 of the American Joint Committee on Cancer were evaluated regarding brain metastasis by history and physical examination and patients in Stage 3, by means of brain MRI, and metastasis was ruled out in all patients included in the study.

In our study we found that S100B serum level was significantly lower in patients with ductal carcinoma in comparison with other types of breast cancers. Based on our knowledge, in no previous study has this relationship been evaluated and reported. This finding should be evaluated in future studies.

Our study had some limitations. First, we just had one serum sample from patients, which was collected at the beginning of treatment course. It would be better to collect serum sample before and after treatment course and compare the levels of $\mathrm{S} 100 \mathrm{~B}$ between them. It is possible that there is a correlation between serum level of S100B after a course of chemotherapy with recurrence and survival rate. Another limitation is the follow-up period, which could be longer in future studies.

\section{Conclusion}

In conclusion, based on our findings serum concentrations of S100B protein may not have any role in breast cancer prognosis prediction including patients' recurrence and survival rate.

\section{Future perspective}

Further studies should be performed to investigate the role of S100B serum level in breast cancer prognosis prediction in larger populations, possibly including both metastatic and nonmetastatic breast cancer patients to compare the results between them for better judgment.

Acknowledgments

This study is part of a research thesis for a Pharm.D. degree at Mashhad University of Medical Sciences.

Financial \& competing interests disclosure

This study is financially supported by Mashhad University of Medical Sciences. The authors have no other relevant affiliations or financial involvement with any organization or entity with a financial interest in or financial conflict with the subject matter or materials discussed in the manuscript apart from those disclosed.

No writing assistance was utilized in the production of this manuscript. 


\section{Open access}

This work is licensed under the Attribution-NonCommercial-NoDerivatives 4.0 Unported License. To view a copy of this license, visit http://creativecommons.org/licenses/by-nc-nd/4.0/

\section{Summary points}

- Cumulative risk of recurrence 5 years after the beginning of the study was 0.86 .

- There was no significant correlation between serum level of S100B protein and recurrence rate $(p=0.59)$.

- Age, BMI, positive family history and number of pregnancies were affective on 5-year survival rate but serum S100B level had an insignificant negative effect in regression equation ( $p$-value $=0.6, \beta=-0.01$ ).

- S100B level was significantly lower in patients with ductal carcinoma in comparison with other histology ( $p$ $=0.035$ ).

- $\mathrm{S} 100 \mathrm{~B}$ serum level was not significantly different in patients who received hormone replacement therapy or in estrogen receptor-positive patients based on independent sample $T$ test $(p=0.857,0.302$, respectively).

\section{References}

Papers of special note have been highlighted as: $\bullet$ of interest; $\bullet \bullet$ of considerable interest

1. Esserman LJ, Joe BN. Clinical features, diagnosis, and staging of newly diagnosed breast cancer. UpToDate (2017) www.uptodate.com/contents/clinical-features-diagnosis-and-staging-of-newly-diagnosed-breast-cancer

2. Ferlay J, Steliarova-Foucher E, Lortet-Tieulent $\mathrm{J}$ et al. Cancer incidence and mortality patterns in Europe: estimates for 40 countries in 2012. Eur. J. Cancer 49(6), 1374-1403 (2013).

3. Kesson EM, Allardice GM, George WD et al. Effects of multidisciplinary team working on breast cancer survival: retrospective, comparative, interventional cohort study of 13722 women. BMJ 344, e2718 (2012).

4. WHO. Breast cancer: prevention and control. www.who.int/cancer/detection/breastcancer/en/index1.html

5. Hayes DF, Trock B, Harris AL. Assessing the clinical impact of prognostic factors: when is 'statistically significant' clinically useful? Breast Cancer Res. Treat. 52(1-3), 305-319 (1998).

6. Li F, Men X, Zhang W. S100 protein in breast tumor. Indian J. Cancer 51(7), 76-71 (2014).

7. Foukakis T, Bergh J, FRCP. Prognostic and predictive factors in early, nonmetastatic breast cancer. (2018) www.uptodate.com/contents/prognostic-and-predictive-factors-in-early-nonmetastatic-breast-cancer

8. Donato R, Cannon BR, Sorci G et al. Functions of S100 proteins. Curr. Mol. Med. 13(1), 24-57 (2013).

9. Yen MC, Huang YC, Kan JY, Kou PL, Hou MF, Hsu YL. S100B expression in breast cancer as a predictive marker for cancer metastasis. Int. J. Oncol. 52(2), 433-440 (2018).

10. Salama I, Malone PS, Mihaimeed F, Jones JL. A review of the S100B proteins in cancer. Eur. J. Surg. Oncol. 34(4), 357-364 (2008).

11. Chen H, Xu C, Jin Q, Liu Z. S100 protein family in human cancer. Am. J. Cancer Res. 4(2), 89-115 (2014).

12. Weide B, Richter S, Buttner $P$ et al. Serum $S 100 B$, lactate dehydrogenase and brain metastasis are prognostic factors in patients with distant melanoma metastasis and systemic therapy. PLoS ONE 8(11), e81624 (2013).

\section{- Evaluates the serum level of $\mathrm{S} 100 \mathrm{~B}$ as a prognostic factor in distant melanoma metastasis.}

13. Miller KD, Weathers T, Haney LG et al. Occult central nervous system involvement in patients with metastatic breast cancer: prevalence, predictive factors and impact on overall survival. Ann. Oncol. 14(7), 1072-1077 (2003).

14. Mcllroy M, McCartan D, Early S et al. Interaction of developmental transcription factor HOXC11 with steroid receptor coactivator SRC-1 mediates resistance to endocrine therapy in breast cancer [corrected]. Cancer Res. 70(4), 1585-1594 (2010).

15. Darlix A, Lamy PJ, Lopez-Crapez E et al. Serum HER2 extra-cellular domain, S100ss and CA 15-3 levels are independent prognostic factors in metastatic breast cancer patients. BMC Cancer 16, 428 (2016).

-. Evaluates the prognostic role of $\mathrm{S} 100$ protein in metastatic breast cancer.

16. Homaei Shandiz F, Ghaffarzadegan K, Jahani Fariman S, Akbarzadeh M, Elyasi S, Mohammadpour AH. Evaluation of serum levels of 8-oxo-2'-deoxygunosine as a prognostic factor in nonmetastatic breast cancer patients. Breast Cancer Manage. 6(2), 71-79 (2017).

17. Mischke D, Korge BP, Marenholz I, Volz A, Ziegler A. Genes encoding structural proteins of epidermal cornification and S100 calcium-binding proteins form a gene complex ('epidermal differentiation complex') on human chromosome 1q21. J. Invest. Dermatol. 106(5), 989-992 (1996).

18. Ahmad O, Wardlaw J, Whiteley WN. Correlation of levels of neuronal and glial markers with radiological measures of infarct volume in ischaemic stroke: a systematic review. Cerebrovasc. Dis. 33(1), 47-54 (2012).

19. Romner B, Ingebrigtsen T, Kongstad P, Borgesen SE. Traumatic brain damage: serum S-100 protein measurements related to neuroradiological findings. J. Neurotrauma. 17(8), 641-647 (2000). 